\title{
IDORT: A SISTEMATIZAÇÃO DE UM PROJETO DE EDUCAÇÃO PARA A CLASSE TRABALHADORA
}

\author{
Eraldo Leme Batista ${ }^{1}$
}

\begin{abstract}
RESUMO: Neste artigo, discorremos sobre a origem de um projeto de organização e sistematização para a formação da classe trabalhadora brasileira. Em nossa pesquisa de Doutorado, realizada na Faculdade de Educação - Unicamp, verificamos que uma instituição empresarial foi pensada e criada na década de 1930, visando à organização de um sistema educacional que formasse a classe trabalhadora para o trabalho taylorizado. O Instituto de Organização Racional do Trabalho - IDORT elaborou esse projeto, tornandoo público, reconhecido e financiado pelo Estado, visando ao progresso e desenvolvimento do Brasil. Utilizamos o Materialismo Histórico Dialético por entendermos ser o melhor método para compreendermos a sociedade em que vivemos, sua metamorfose e para compreendermos o período histórico da pesquisa, ou seja, as décadas de 1930 e 1940. Concluímos que o IDORT, foi, por excelência, uma Instituição Educacional Profissional de grande relevância para a disseminação do projeto da burguesia industrial para o país. Palavras-chave: IDORT. Educação profissional. Racionalização. Taylorismo.
\end{abstract}

\section{IDORT: SYSTEMATIZATION OF A PROJECT OF EDUCATION FOR THE WORKING CLASS}

ABSTRACT: In this article, we discuss the origin of a project of organization and systematization for the formation of the Brazilian working class. In our PhD research carried out in the Faculty of Education - Unicamp, we verified that a business institution was thought and created in the decade of 1930, aiming at the organization of an educational system that formed the working class for the Taylorized work. The Institute for Rational Labor Organization (IDORT) elaborated this project, making it public and recognized, financed by the State, aiming at the progress and development of Brazil. We use Dialectical Historical Materialism because we believe that it is the best method to understand the society we live in, its metamorphosis, and to understand the historical period of the research, that is the 1930s and 1940s. We conclude that IDORT was a Professional Education Institution of great relevance for the dissemination of the project of the industrial bourgeoisie to the country.

Keywords: IDORT. Professional education. Rationalization. Taylorism

\footnotetext{
${ }^{1}$ Prof. Dr. do Mestrado em Educação da Universidade do Vale do Sapucaí - Univas - MG. E-mail: eraldolbatista@gmail.com
} 
IDORT: LA SISTEMATIZACIÓN DE UN PROYECTO DE EDUCACIÓN PARA LA CLASE TRABAJADORA

RESUMEN: En este artículo, discordamos sobre el origen de un proyecto de organización, sistematización para la formación de la clase trabajadora brasileña. En nuestra investigación de Doctorado, realizada en la Facultad de Educación - Unicamp, verificamos que una institución empresarial fue pensada y creada en la década de 1930, buscando la organización de un sistema educativo que formase a la clase trabajadora para el trabajo taylorizado. El Instituto de Organización Racional del Trabajo - IDORT elaboró ese proyecto, haciéndolo público y reconocido y financiado por el Estado, buscando el progreso y desarrollo de Brasil. En el siglo XVIII, en el siglo XVIII, en el siglo XVIII, en el siglo XVIII, en el siglo XVIII, una Institución Educativa Profesional de gran relevancia para la diseminación del proyecto de la burguesía industrial para el país.

Palabras clave: IDORT. Educación profesional. Racionalización. Taylorismo.

\section{Introdução}

O crescimento de um projeto que visava à industrialização do Brasil contribuiu para o processo acelerado de urbanização dos municípios, transformando algumas cidades em metrópoles, caso de São Paulo e Rio de Janeiro, já no limiar do século XX. Esse processo contribuiu para a saída em massa do meio rural, que estava em crise, em busca por melhores condições de vida ou mesmo a sobrevivência. As indústrias foram crescendo, novos maquinários foram importados da Europa, contribuindo para aumentar a produção e o processo tão almejado da industrialização brasileira. Porém, um dos problemas encontrados nessa fase inicial, foi a escassa força de trabalho com capacitação, conhecimento de como utilizar esse maquinário ou como trabalhar nessas fábricas, o que exigia certa preparação, diante de um cenário onde a classe trabalhadora em sua maioria era analfabeta. Surgiu daí o discurso apaixonado da burguesia industrial em defesa da educação, da escola para os filhos da classe trabalhadora, pois todos eles, crianças, jovens e adultos, deveriam trabalhar na produção industrial. Mas, como alcançar objetivo tão amplo?

A formação profissional existente até aquele período era mais doméstica, artesanal e deficitária, muito básica para uma indústria que se pretendia altaneira. Nesse período, a importação de trabalhadores seria impedida pelos altos valores a serem pagos a essa força de trabalho, valores que não correspondiam à realidade brasileira, tornando-se assim, necessário e menos oneroso investir na formação de trabalhadores nacionais, que tinham à frente lindos campos floridos e possibilidade concreta de progresso virtuoso.

Os olhos burgueses refletiam cifras, acumulação, lucros a partir do sonho americano de vida, 
o american way of life - o sonho de um país pensado pelo industrial Henry Ford - ou seja, o país industrial, com os trabalhadores cumprindo seu papel, trabalhando e trabalhando, labutando sempre e sonhando - ao olhar para o lindo céu anil - com a possibilidade de um dia vencer na vida. Neste contexto, esperavam formar milhões de indivíduos ideologicamente "corretos", aptos e adeptos do processo burguês que partilhariam um dia, num futuro não tão distante, o bolo para todos.

Entendemos que nesse período histórico, tornou-se necessário formar os filhos da classe trabalhadora, não para a ascensão social, mas para o trabalho. Nesse sentido, foi gestada uma instituição visando pôr em prática esse projeto. Era, portanto, necessário formar esse trabalhador e capacitá-lo sob a égide da racionalização do trabalho. Se o trabalhador lá na roça, no meio rural, planejava apenas o seu trabalho do dia seguinte, o que faria ele, o que fariam a esposa e filhos, desde a manhãzinha, na indústria? Esse modo de pensar o trabalho não caberia mais no novo contexto, uma vez que ele se especializaria em produzir bem, com mais afinco e dedicação e acreditando que um dia a vida seria melhor.

Lembramos que, desde o inicio do século XX, a questão da formação dos trabalhadores para o trabalho na indústria, já se fazia presente. A Lei n¹.184, de 3 de Dezembro de 1909, já apontava para a preocupação de educação dos jovens filhos dos trabalhadores:

Esta lei determinou a criação de escolas noturnas, na capital e no interior, especificando que elas deveriam localizar-se nas proximidades das fábricas e atenderem, exclusivamente, aos meninos operários ou filhos de operários. A prioridade de instalação dessas escolas seria daquelas que tivessem acomodações oferecidas pelas empresas, e o professor seria sempre provido pelo governo estadual. A articulação com as fábricas deveria se dar, também, na definição do horário escolar (CUNHA, 2005a, p. 141).

Em sua pesquisa, Cunha (2005a) nos informa que o texto da lei $n^{\circ} 1.192$, de 22 de dezembro de 1909, expressava a persistência da ideia do ensino profissional como algo destinado aos desvalidos, em consonância, aliás, com a exposição de motivos do decreto do presidente de República desse mesmo ano:

Fica o Governo autorizado a contratar com estabelecimentos industriais, agrícolas ou beneficentes de reconhecida idoneidade, a educação profissional de menores pobres, não criminosos de ambos os sexos, que tenham mais de 11 anos de idade e que, por falta de proteção paterna ou tutelar, estiverem abandonados (CUNHA, 2005a, p. 142). 
A preocupação com a formação do trabalhador foi ganhando maior importância, em 1911, quando foi sancionado

[...] o decreto $\mathrm{n}-9070$ [que] regulamentava as escolas de aprendizes artífices e ampliava alguns pontos do decreto no 7.566 , assinado por Nilo Peçanha. Em São Paulo, eram inauguradas as Escolas Profissionais Masculina e Feminina, que posteriormente passariam a denominar-se "Escola Técnica Getúlio Vargas" e "Escola Técnica Carlos de Campos" (SENAl, 1991, p. 114 - Grifos nosso).

Em 1920, criou-se uma comissão, cujo objetivo era acompanhar o trabalho das escolas profissionalizantes existentes. A partir dos relatórios dessa comissão, criou-se em 1921 o Serviço de Remodelação do Ensino Profissional Técnico (SENAI, 1991, p. 114). Em decorrência do trabalho minucioso da Comissão, ela foi transformada em 1931 em:

'Inspetoria do Ensino Profissional Técnico', chefiada por Francisco Montojos. Em 1934, o decreto no 24.558 transformava a 'Inspetoria do Ensino Profissional Técnico' em 'Superintendência do Ensino Profissional Técnico', subordinada diretamente ao Ministério da Educação e Saúde Pública (SENAI, 1991, p. 114 - grifos do autor).

Portanto, é fácil compreender que o debate e a defesa de uma educação profissional foram crescendo no país, desde o início do século XX, sendo que o Instituto de Organização Racional do Trabalho $(\text { IDORT) })^{2}$ foi a concretização de um projeto que deveria sistematizar o pensamento dos industriais, torná-lo palatável para que todos pudessem ingerir saborosamente as ideias de racionalização da sociedade e, claro, do trabalho, contidas nele.

Assim, a Educação profissional ${ }^{3}$ torna-se a vedete dos industriais, um projeto que formaria uma massa de trabalhadores que tocariam as fábricas, mantendo acesas as chaminés da produção e o

\footnotetext{
2 O IDORT tinha como um dos seus objetivos "[...] estabelecer um novo paradigma para nortear as relações entre as classes sociais. Ao invés do conflito, das lutas de classes tão evidentes naquele período histórico, buscava-se a conciliação entre as classes, fator igualmente fundamental para a aceleração do desenvolvimento industrial” (PICHELLI, 1997, p. 15-16).

${ }^{3}$ A principal referência do IDORT, com relação à educação profissional, foi Roberto Mange: "o introdutor dos métodos tayloristas nas instituições de formação profissional e na organização do trabalho no Brasil [...] nasceu em 1885, na cidade suíça de La Tour-de-Peilz. Filho de um Diplomata, fez seus estudos na Alemanha [...] Contratado em 1903, com a idade de 28 anos, para lecionar desenho de máquinas na Escola Politécnica de São Paulo, influenciou várias gerações de engenheiros que, após passarem por suas mãos, ocuparam altas cargos na burocracia estatal e nas empresas públicas (BRYAN, 2008, p. 25).
} 
aumento das riquezas da ávida burguesia. Portanto, a defesa dos industriais do ensino industrial em São Paulo e posteriormente no Brasil, dava-se a partir da necessidade de ter operários capacitados para essa indústria que cresceria e tomaria todos os cantos do país, levando para todos a possibilidade de construir uma nação rica e altaneira.

A Educação profissional passa, assim, cada vez mais a ser um instrumento de controle social. Souza entende que:

[...] o projeto pedagógico da burguesia sempre funcionou para além dos interesses imediatos da produção, buscando as condições necessárias para que isto se cumprisse com eficácia, como um projeto de direção moral, cultural e ideológica para toda a sociedade. Nesse sentido, a ação pedagógica liberal procura legitimar a ideia de que não existem contradições entre as classes, sendo a harmonia preservada pela força de um discurso que reifica as desigualdades, tomando-as como resultado natural das diferentes formas de inserção dos sujeitos na esfera produtiva (SOUZA, 2012, p. 7-8).

Entendemos que tornou-se instrumento, pois sabiamente, os industriais ligaram o discurso de desenvolvimento do país à necessidade da educação de todos, para uma sociedade educada, instruída, civilizada. Contestar o projeto burguês não era tarefa fácil, pois seria incorrer no risco de negar o projeto de formação dos trabalhadores para o trabalho, desejo de todos que almejavam trabalhar e ter uma vida mais digna e melhor.

Ao analisarmos esse período histórico e a questão da educação profissional no Brasil, verificamos que criou-se um discurso da importância da educação e da educação profissional para capacitar os aprendizes para o trabalho nas fábricas. Nessa efervescência do desejo de educação para todos, gratuita e oferecida pelo Estado é que se tornam referência as teses dos escolanovistas apregoadas principalmente no Manifesto dos Pioneiros da Educação Nova de 1932. Com o movimento da escola nova, a marcha para o "progresso" e para o "desenvolvimento" teria que passar necessariamente pela educação escolar.

Por fim, as marcas da modernidade apareciam na fisionomia brasileira: entre o passado e o futuro, um presente incendiado de idéias. A máquina, a fábrica, a técnica, a democracia liberal, o sufrágio esclarecido, a educação enquanto dever do Estado, a marcha do progresso, tudo foi aceito e tornado público (MONARCHA, 1990, p. 137).

Neste período histórico, o país vivenciava o crescimento das indústrias e das fábricas menores, que prestavam trabalho para essas indústrias. Aumentando a produção, tornava-se 
obrigatória uma quantidade considerável de trabalhadores aptos para o trabalho fabril. Foi nesse contexto de crescimento das ideias e defesa da educação escolar e educação profissional que ocorre a Reforma da educação, conhecida como Capanema ou Leis Orgânicas do Ensino. Tal Reforma organizou o ensino técnico profissional em três áreas da economia, criando as seguintes Leis Orgânicas: Ensino Industrial (Decreto-lei 4.073/42), Ensino Comercial (Decreto-lei 6.141/43) e Ensino Agrícola (Decreto-lei 9.613/46). Esses cursos continham dois ciclos: um fundamental, geralmente de quatro anos, e outro técnico, de três a quatro anos. Apesar da significância de se investir no nível técnico, essa Reforma não conseguiu resolver os problemas sérios que surgiram nesse nível de ensino, pois havia falta de flexibilidade com o ensino secundário e restringia o acesso ao nível superior, uma vez que as Leis Orgânicas só permitiam tal acesso a cursos do ramo profissional correspondente.

Embora seja exaltada a importância e relevância da Reforma, ela não sanou os diversos problemas existentes naquele período referentes ao ensino técnico, pois - como já dito - não havia uma articulação ou consonância com o ensino secundário, além de limitar e restringir o acesso à educação superior, que, portanto, tornava-se cada vez mais elitizada. A proposta das Leis Orgânicas, inviabilizando o acesso aos cursos superiores, portanto, era formar quadros técnicos, formação limitada para apenas determinadas funções e restritas profissões.

Ao estudarmos o cenário político, social e econômico do Brasil, na década de 1930, nos deparamos com uma sociedade, demonstrando as mudanças ocorridas no país, quando milhões de pessoas migraram para grandes centros urbanos, contribuindo para o processo de urbanização e industrialização, processo migratório mais efetivo após a segunda guerra mundial. Neste contexto, a maior parte dos trabalhadores não possuía uma formação definida e específica e o sistema educacional, ainda incipiente e precário, não atendia à demanda existente. Sendo assim, o governo brasileiro recorreu à institucionalização de agências educacionais profissionalizantes, em consonância com o sistema oficial, a fim de preparar essa força de trabalho de modo rápido e eficaz.

Constatamos também que na década de 1930, o Governo Federal elaborou um anteprojeto visando regulamentar o ensino profissional. Para tanto, enviou-o para os industriais opinarem sobre seu conteúdo antes de ser sancionado. No entanto, por divergências políticas com o Governo Vargas, os industriais organizados na Confederação Nacional da Indústria (CNI) e a Federação das Indústrias do Estado de São Paulo (FIESP) não contribuíram com o governo central, por discordância do projeto e da forma como foi elaborado. Tratava-se de um jogo de poder, pois os industriais exigiam mais espaços e poder no aparelho de Estado governado por Vargas (MANFREDI, 2002). 
Ocorria também, nesse período histórico, uma acirrada disputa política entre o Ministério do Trabalho e o Ministério da Educação, tendo como principal motivo a responsabilidade da organização, implementação e gestão da educação profissional no país. Ao tratar dessa questão, Müller (2009, p. 138) nos informa que estava em jogo uma disputa entre frações de classe no interior do governo:

\begin{abstract}
A disputa dos ministros pode ser entendida como um embate entre frações do próprio capital tentando se acomodar, ou seja, uma "queda de braço" para verificar quem mantinha a hegemonia para dominar o grupo adversário. No caso, quem estava mais próximo ao Estado, conquistou essa hegemonia, sendo que o embate terminou pelo arbítrio do próprio presidente Vargas, que optou pelo Ministério do Trabalho, Indústria e Comércio para negociar com os empresários. Esses acabaram aceitando as normas impostas pelo referido Decreto, assumindo, sem outra opção, os custos financeiros pela formação profissional de seus operários. Assim, em 26 de julho de 1940 foi assinado o Decreto 6.029/40 que regulamentava a instalação e funcionamento de cursos profissionalizantes previstos no Decreto $1.238 / 39$, porém com algumas mudanças que poderiam orientar as indústrias no cumprimento do disposto. Definia-se ali, ainda, a função de aprendiz como trabalhador ligado à indústria, mas com carga horária diária e salários diferenciados.
\end{abstract}

Nas disputas no interior do Estado, os industriais ocupam, gradativamente, os espaços estratégicos, sendo que em 1942, por exemplo, em convênio com a Confederação Nacional das Indústrias, através do Decreto-Lei 4.048 de 1942, foi criado o Serviço Nacional de Aprendizagem Industrial (SENAI) e, quatro anos depois, o Serviço Nacional de Aprendizagem Comercial (SENAC), pelo Decreto-Lei 8.621 de 1946, dirigido e organizado pela Confederação Nacional do Comércio. Tratam-se de instituições criadas visando atender à demanda de qualificação para o trabalho, em todos os níveis de profissionalização. Atualmente, são responsáveis pela maior rede de escolas de educação profissional no Brasil.

A partir do exposto, consideramos que importantes iniciativas do governo Vargas e dos industriais foram tomadas para que a educação profissional fosse implantada como um projeto de formação da classe trabalhadora atrelada aos interesses do capitalismo industrial em crescimento. Observamos ainda que, além das reformas do ensino, outros fatos históricos desse período são consideráveis e importantes para entendermos como se gestou e se desenvolveu a educação profissional em nosso país. Destacamos o papel fundamental do IDORT, como uma instituição que desenvolveu todo o projeto de educação profissional na década de 1930, contribuindo para o seu desenvolvimento posterior. 


\section{A importância do IDORT como instituição educacional}

Foi no contexto histórico, político e social da década de 1930 que surgem as propostas articuladas pelos industriais paulistas, para a criação de uma entidade que defendesse a organização e a racionalização do trabalho a partir das concepções tayloristas, advogando o surgimento de uma sociedade baseada no industrialismo, que estava em expansão naquele período. Alguns nomes da elite industrial, como Aldo Mário de Azevedo, Roberto Simonsen, Roberto Mange ${ }^{2}$ e Armando de Salles Oliveira, defendiam a constituição de uma sociedade racional. Um dos que mais contribuíram para a organização de sua classe no país foi Simonsen, entusiasta da racionalização, utilizando o método e as técnicas tayloristas em sua empresa desde o início do século XX. Exemplo disso foi a experiência que desenvolveu com a construção de diversos quartéis militares em 1923 no Brasil. Foram utilizadas, nesse processo, inúmeras técnicas e métodos de organização racional, padronizando a construção, o que resultou na redução de custos e na conclusão das obras em menor tempo (MEDEIROS, 1980, p. 125).

Simonsen também foi um dos responsáveis pela "criação da Escola Livre de Sociologia e Política de São Paulo, em 1933, com o sentido de preparar a elite empresarial para a atividade industrial" (VARGAS, 1985, p. 169). Em 1918, discursou aos operários da Companhia Construtora de Santos sobre a necessidade da racionalização do trabalho, além de criticar a luta de classes e propor a cooperação entre empresários e trabalhadores em torno das ideias da racionalização. Nesse momento, Simonsen chamava a atenção do empresariado nacional para a situação do pós-guerra, quando, diante da perspectiva de "evitar a todo transe que sejam trazidas para o nosso Brasil as lutas de classe", diante da "tremenda luta econômica que se vai travar", impunha a necessidade da moderna organização do trabalho. Estruturar as empresas para a "máxima economia na produção pela racionalização da máxima eficiência" implicava novas relações com os trabalhadores, para que "imperem os verdadeiros princípios da cooperação entre patrões e operários" (ANTONACCI, 1993, p. 37).

\footnotetext{
2 Roberto Mange estava entre os fundadores da nova instituição, trazendo sua experiência na aplicação dos métodos psicotécnicos de seleção profissional, levada a efeito no Liceu de Artes e Ofícios de São Paulo, desde 1923, e no Serviço de Ensino e Seleção Profissional da Estrada de Ferro Sorocabana, em funcionamento desde 1930.
} 
Esse industrial defendia, em seus trabalhos, palestras e conferências, a importância de aperfeiçoar o método do trabalho, de seleção profissional e também de desenvolver uma técnica pedagógica que estivesse a serviço dos industriais, visando maior produtividade.

A prosperidade do Brasil no pós-guerra enfatizava novos métodos de produção, mais científicos e eficientes, que acarretariam a elevação tanto dos lucros quanto do padrão de vida dos trabalhadores, já que [...]

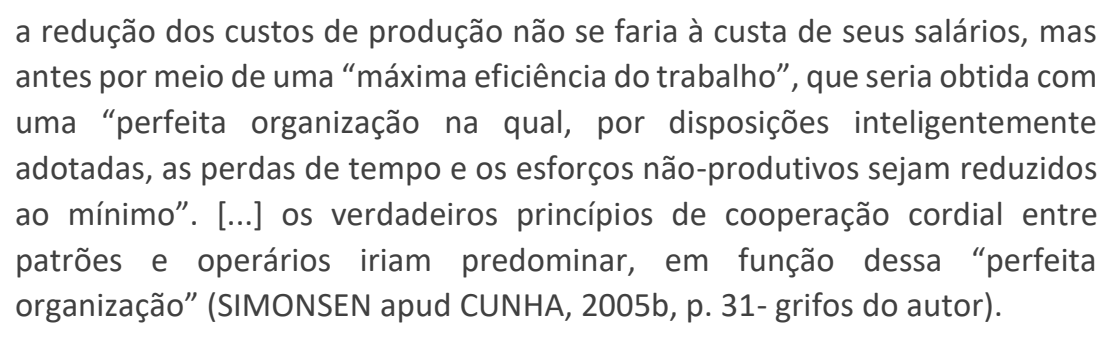

Percebemos o entusiasmo pelas ideias tayloristas, na defesa da colaboração de classes, de cooperação cordial, como mecanismo para viabilizar o projeto de racionalização no país, possibilitando, assim, a elevação dos lucros. Como se vê, ocorria nesse período um processo acelerado de organização dos industriais. Verificamos que no decorrer dos anos de 1920 já discutiam a necessidade de estarem mais organizados enquanto classe.

Um dos principais intelectuais que contribuíram para a organização e elaboração de um projeto para a educação profissional no Brasil foi Roberto Mange, que não mediu esforços objetivando desenvolver as experiências de racionalização taylorista na formação dos trabalhadores. Trata-se de uma referência na área porque, além de ser um importante pensador e idealizador do referido projeto, era uma pessoa que tinha trânsito com todos os setores da burguesia industrial nacional. Liderança reconhecida no meio, além de um entusiasta das ideias de Taylor e defensor do movimento pela administração científica do trabalho.

Ao apresentar Roberto Mange como sendo um dos inquiridos em uma pesquisa sobre o ensino profissionalizante, Fernando Azevedo apresenta diversos elogios ao seu trabalho:

Para quem conhece de perto ou apenas visitou a Escola Profissional Mecânica, do Liceu de Artes e Ofícios, o depoimento de hoje, sobre este ramo de ensino, tem duplo interesse. Já bastava para revesti-lo de autoridade, ser de um especialista a mão que o traçou. Mas, ele não reflete somente o pensamento do engenheiro mecânico, que tem prestado à Escola Politécnica de São Paulo, no exercício do magistério, o concurso de sua matéria, dobrado 
prestígio é o fato de concorrerem ao Dr. Roberto Mange o saber técnico de um especialista em máquinas e o espírito de organização, positivo e luminoso, a que se deve, em São Paulo, a mais bela tentativa nos domínios do ensino profissional mecânico. Embora de iniciativa privada e fundação recente, a Escola Profissional Mecânica tende, de fato, a transformar-se em paradigma das escolas desse gênero. Não é a obra de improvisação impelida, sem objetivo claro, ao capricho das circunstâncias. É empreendimento que obedece, nos menores detalhes, a um plano de idéias seguras e precisas. Tudo o que ali se realiza, atinge, por isto, resultados certos como os que coroaram a execução, pela primeira vez entre nós, dos métodos de seleção profissional baseados na psicologia e fisiologia aplicadas ao trabalho (AZEVEDO, 1957, p. 149).

O prestígio de Mange junto aos educadores escolanovistas e aos industriais era tanto que, em vez de se ouvir o diretor da mais importante escola pública profissional de São Paulo, quem é convidado e participa do inquérito é o próprio Mange. Gonzaga tinha uma visão mais independente, era mais crítico com relação à formação dos trabalhadores, enquanto Mange defendia e buscava implementar o projeto definido pela elite industrial ligada ao IDORT.

Foi a visão de Mange sobre treinamento profissional que se firmou como a tendência predominante no Brasil. [...]. Assim, não é de se surpreender que Fernando Azevedo tenha entrevistado Mange e não Gonzaga (que, afinal de contas, era o diretor da mais importante escola pública profissional de São Paulo) em sua pesquisa. Foi a entusiástica campanha de Roberto Mange pela organização racional que atraiu os educadores brasileiros mais inovadores, que procuravam criar para o país um sistema educacional perfeitamente moderno (WEINSTEIN, 2000, p. 56).

A partir do trabalho que realizamos, entendemos que o IDORT, foi estratégico, fundamental e a principal instituição a organizar, sistematizar, divulgar e defender as ideias sobre a importância da formação da classe trabalhadora, além de ser uma entidade que defendia entusiasticamente as teses sobre a racionalização do trabalho.

A partir de todo o esforço dos industriais é que na década de 1940 conseguiram, mesmo não concordando com a centralização da discussão nas mãos do Estado, criar uma importante escola de formação dos trabalhadores. Por apoiar Vargas no Estado Novo (1937-1945), os industriais conseguiram avanços em seus projetos, como por exemplo, regulamentar as propostas de ensino profissional no Brasil, a partir da reforma Capanema (1942) que estruturou o ensino profissional, reformulou o ensino comercial e criou o SENAI.

O projeto defendido pelo IDORT era que, desde a infância, as crianças tivessem acesso de 
forma sistematizada e pedagógica, às ideias de organização racional. Tratava-se de um projeto que realmente visava "inculcar" na criança, a partir da escola, quais seriam suas únicas possibilidades de sobrevivência na sociedade capitalista. Para os filhos da classe que vendia sua força de trabalho, a única alternativa era aceitar o projeto defendido pelo IDORT, onde estavam presentes todos os princípios da ética para o trabalho, do próprio trabalho, sendo que o serviço de orientação deveria também se preocupar com o perfil psicológico dos futuros operários: ou eles se adequavam, aceitavam as regras e se comprometiam com os pressupostos presentes nas orientações idortianas ou ficariam excluídos da indústria fabril. Essa questão está clara e explícita na Revista do IDORT (1932, p. 4): “[...] a cooperação com as escolas para tornar conhecidas as profissões normais da cidade e do pais; levantamento do cadastro e elaboração do perfil psicológico das diferentes profissões; trabalhos para guiar os candidatos na escolha certa". Ainda conforme a revista:

Análise do trabalho nas várias profissões para verificação das aptidões básicas de cada uma, seleção por meio de testes, de candidatos a determinadas profissões, tais como: aprendizes e operários industriais, condutores de veículos, telefonistas, telegrafistas, ferroviários, agentes de segurança, aviadores etc; colaboração na organização de cursos de educação profissional, tendo em vista, o desenvolvimento racional das aptidões na base psicotécnica, bem como a aquisição metódica de conhecimentos técnoprofissionais; verificação da eficiência de provas e métodos psicotécnicos; determinados padrões profissionais (valores médios) em nosso meio. (REVISTA IDORT, 1932, p. 1-2).

A partir da Revista IDORT, os empresários disseminavam suas propostas e projetos que eram esmiuçadas pelos seus intelectuais orgânicos, desqualificando os discursos operários, a cultura popular, visando criar outra sociedade, um homem passivo. Tratava-se de um projeto que visava transformar o operário em um ser dócil, disciplinado, colaborador, patriota e, acima de tudo, que não compactuasse das ideias "estranhas" dos trabalhadores estrangeiros.

Cabe acrescentar que as propostas, ideias, projetos definidos pelo referido Instituto, eram divulgadas via Revista IDORT, criada e lançada na cidade de São Paulo em janeiro de 1932. Tratava-se de uma revista com edição mensal, distribuída aos sócios do instituto e enviada aos diretores das empresas a ele vinculadas. O endereço da revista era o mesmo do instituto: Rua Senador Feijó, 27, 3o andar, São Paulo/SP. 
Conforme editorial da revista número 1, esta seria a publicação oficial do IDORT:

Registrar-se-à a actividade e divulgará o que de mais interessante se realiza no mundo da matéria. Os nossos sócios sempre encontrarão nella espaço para apresentar seus estudos e observações, referentes à organização scientifica do trabalho. Idort será a revista de todos aquelles que, comprehendendo a significação desta campanha por melhorar, desejam progredir com a mesma velocidade da civilização actual (REVISTA IDORT, 1932, p. 1).

A estrutura da Revista IDORT, nas décadas de 1930 e 1940, não sofreu muitas modificações. Foram editadas, de janeiro de 1932 a dezembro de 1942, 132 revistas em edições mensais, o que constitui seu universo. A partir de 1942, passou a ser publicada com o título Revista de Organização Científica, e não mais Revista IDORT. Lembramos que ela foi editada até o ano de 1981, totalizando 595 edições. Todas as ações, atividades realizadas pelo Instituto eram divulgadas pela revista que também publicava artigos de engenheiros, empresários e intelectuais que defendiam a organização racional do trabalho. Essa revista foi referência para os industriais paulistas, passando a ser fonte de informações de industriais de outros Estados que adotavam as ideias de racionalização em suas fábricas.

\section{Considerações Finais}

Ao concluirmos nossa pesquisa de doutorado, verificamos que o Instituto de Organização Racional do Trabalho tornou-se de fato uma instituição de "excelência", do pensamento burguês, sendo, portanto, uma instituição educacional que discutia, analisava, elaborava e difundia o projeto de educação que queria tanto para a classe trabalhadora, como para a elite do país, principalmente de São Paulo.

O IDORT, tornou-se o centro das atenções, por centralizar e conseguir sistematizar, mesmo nas divergências, as ideias do pensamento industrial burguês do período. A atuação do IDORT extrapolou as ações da burguesia, sendo reconhecida por setores da sociedade, como os comerciários e professores, tornando-se um partido político dessa burguesia brasileira, ao elaborar programas e projetos para diversas áreas da sociedade, produção racional e também para a educação, contando principalmente com a colaboração dos escolanovistas (Lourenço Filho, Fernando Azevedo, Anísio Teixeira e Noemy da Silveira Rudolfer), além de professores da Escola Politécnica da USP. 
Com o IDORT, foi possível a elaboração de um projeto sistematizado de educação profissional para o país, sendo que seus principais expoentes eram Roberto Mange e Lourenço Filho, além do apoio considerável de Fernando de Azevedo e Noemy da Silveira, ou seja: a proposição para a educação brasileira, o manifesto dos pioneiros e toda a proposta para as leis orgânicas foram traçadas a partir do IDORT.

A educação foi um viés privilegiado na defesa e consolidação do projeto industrialista no país. Diversas frentes foram traçadas para a realização desse projeto estratégico. Fernando de Azevedo foi um dos que estiveram à frente do Manifesto dos Pioneiros, defendendo uma educação racional. Lourenço Filho e Roberto Mange estavam à frente da discussão da educação profissional, desenvolvendo experiências e avançando com propostas. Já o engenheiro, industrial e político Roberto Simonsen encabeçava outra frente, como sempre lutando pelas ideias de racionalização e formação de uma elite de administradores da grande indústria. Armando de Salles Oliveira, primeiro presidente do IDORT e interventor do Estado a pedido de Vargas, foi fundamental para a viabilização do projeto esboçado no IDORT.

A partir da pesquisa que realizamos, concluímos que o IDORT foi uma instituição educacional por excelência, por ter desenvolvido projetos educacionais, principalmente na educação profissional, e por defender, divulgar e viabilizar - via articulação política - a construção de um projeto político que fundou a Universidade de São Paulo, a Escola de Sociologia Política e o SENAI, além de todas as demais escolas do Sistema S.

\section{Referências}

ANTONACCI, M. A. M. A Vitória da razão? O IDORT e a sociedade paulista. São Paulo: Marco Zero, 1993.

AZEVEDO, F. A educação na encruzilhada. São Paulo: Melhoramentos, 1957.

BRASIL. Decreto-lei n. 4.048, de 22 de janeiro de 1942. Cria o Serviço Nacional de Aprendizagem dos Industriários (SENAI). Presidência da República, Rio de Janeiro, 22 de janeiro de 1942, 121이 da Independência e 54으 da República.

Decreto-lei n. 4.073, de 30 de janeiro de 1942. Lei Orgânica do Ensino Industrial. Presidência da República, Rio de Janeiro, 30 de janeiro de 1942, 121ㅇ da Independência e 54으 da República.

Decreto-lei n. 6.141, de 28 de dezembro de 1943. Lei Orgânica do Ensino Comercial. Presidência da República, Rio de Janeiro, 28 de dezembro de 1943, 122으 da Independência e 55으 da República. 
Decreto-lei n. 8.621, de 10 de janeiro de 1946. Dispõe sobre a criação do Serviço Nacional de Aprendizagem Comercial (SENAC) e dá outras providencias. Presidência da República, Rio de Janeiro, 1946.

Decreto-lei n. 8.622, de 10 de janeiro de 1946. Dispõe sobre a aprendizagem dos comerciários, estabelece deveres dos empregadores e dos trabalhadores menores relativamente a essa aprendizagem e dá outras providências. Presidência da República, Rio de Janeiro, 1946.

. Decreto-lei n. 9.613 de 20 de agosto de 1946. Lei Orgânica do ensino agrícola. Presidência da República. Presidência da República, Rio de Janeiro, 1946.

CUNHA, L. A. O ensino de ofícios artesanais e manufatureiros no Brasil escravocrata. São Paulo: Ed. Unesp, 2005a.

. O ensino de ofícios nos primórdios da industrialização. São Paulo: Unesp, 2005b.

MANFREDI, S. M. Educação profissional no Brasil. São Paulo: Cortez, 2002.

MEDEIROS, M. M. Estradas de Ferro e Ensino Industrial: Um Estudo de Caso. 1980. 267f. Tese (Doutorado em Educação). Fundação Getúlio Vargas, Rio de Janeiro, 1980.

MULLER, M. T. A Lousa e o torno: a escola SENAI Roberto Mange de Campinas. 2009. 334 f. Tese (Doutorado em Educação). Faculdade de Educação. Universidade Estadual de Campinas, Campinas, 2009.

MONARCHA, C. A reinvenção da cidade e da multidão. Dimensões da modernidade brasileira: a Escola Nova. São Paulo: Cortez: Autores Associados, 1990.

PICHELLI, V. O Idort enquanto proposta educacional no contexto de formação da hegemonia burguesa no Brasil (1930-1944). 1997. 157f. Tese (Doutorado em Educação). Faculdade de Educação, Universidade Estadual de Campinas, Campinas, 1997.

REVISTA IDORT. O QUE SOMOS, №1, jan. 1932.

REVISTA IDORT. PELA COOPERAÇÃO: A Guerra Econômica e o Instituto de Organização Racional do Trabalho de São Paulo, no 2, fev.1932, p. 1 - 2.

REVISTA IDORT. PELA COOPERAÇÃO: A Guerra Econômica e o Instituto de Organização Racional do Trabalho de São Paulo, no 2, fev.1932, p. 4.

SÃO PAULO. Lei no 1.184, de 3 de dezembro de 1909. Crea cincoenta escholas preliminares, nocturnas, para creanças e dá outras providencias. Palacio do Governo do Estado de São Paulo, aos 03 de Dezembro de 1909.

SÃO PAULO. Lei no 1.192, de 22 de dezembro de 1909. Crêa Institutos Profissionaes para menores. Palacio do Governo do Estado de São Paulo, aos 22 de Dezembro de 1909.

SENAI. De homens e máquinas: Roberto Mange e a Formação Profissional. São Paulo: SENAI, 1991.

O giz e a graxa: meio século de educação para o trabalho / Projeto Memória SENAI-SP. São Paulo: SENAI, 1992.

SOUZA, E. G. de. Relação trabalho-educação e questão social no Brasil: Uma leitura do pensamento pedagógico da Confederação Nacional da Indústria - CNI (1930-2000). 2012. 329 f. Tese (Doutorado em Educação). Faculdade de Educação, Universidade Estadual de Campinas, Campinas, 2012. 
VARGAS, N. Gênese e difusão do taylorismo no Brasil. Revista Ciências Sociais Hoje. São Paulo: Anpocs / Cortez, 1985.

WEINSTEIN, B. (Re)formação da classe trabalhadora no Brasil, 1920-1964. São Paulo: Cortez: CDAPHIFAN, 2000.

ZUCCHI, B. B. O programa e os métodos de treinamento profissional do curso de ferroviários da Companhia Sorocabana (São Paulo, Década de 1930). 2007. 111f. Dissertação (Mestrado em Educação). Pontifícia Universidade Católica de São Paulo, São Paulo, 2007.

Recebido em: 28/08/2017

Aceito em: 04/02/2018. 